\title{
A rare case of left coronary sinus Valsalva aneurysm in a woman
}

\author{
Henrik Jensen, MD, PhD, ${ }^{\mathrm{a}, \mathrm{b}, \mathrm{c}}$ Emmanuel Moss, MD, ${ }^{\mathrm{a}, \mathrm{b}}$ and Philippe Demers, MD ${ }^{\mathrm{a}, \mathrm{b}}$
}

Sinus Valsalva aneurysms (SVAs) are rare cardiac malformations observed in $0.09 \%$ of autopsies. ${ }^{1}$ SVAs are often diagnosed during evaluation of associated cardiac abnormalities requiring surgery, and the incidence is up to $1.5 \%$ in surgical series. ${ }^{2}$ The pathognomonic histologic finding is lack of continuity between the annulus fibrosus and the muscular and elastic aortic media. ${ }^{3}$ SVA formation is associated with perimembranous ventricular septal defect, bicuspid aortic valve, aortic regurgitation, and coarctation of the aorta. ${ }^{4}$ SVAs originate from the right coronary sinus in $70 \%$ of patients, the noncoronary sinus in $25 \%$ of patients, and the left coronary sinus in only $5 \%$ of patients, and the male to female ratio is $4: 1{ }^{4}$ SVAs are usually clinically silent and detected by routine 2 -dimensional echocardiography.

\section{CLINICAL SUMMARY}

A 68-year-old woman with previous patch repair of coarctation of the aorta at the age of 17 years was referred for aortic valve replacement. The patient was in New York Heart Association class II/IV, had atypical angina pectoris without relation to physical activity, and had no history of syncope or palpitations. Physical examination results were normal, including normal lower-extremity pulses.

\section{IMAGING}

Transthoracic echocardiography showed an ejection fraction of $65 \%$, a bicuspid aortic valve with an opening area of $0.96 \mathrm{~cm}^{2}$, and a mean gradient of $42 \mathrm{~mm} \mathrm{Hg}$. The patient had mild mitral, tricuspid, and pulmonary valve regurgitation and trace aortic regurgitation. A secundum atrial septal defect measuring $1.2 \times 0.9 \mathrm{~cm}$ was identified. Coronary angiography revealed right dominance and no coronary artery disease. An SVA with an ostium of $9 \mathrm{~mm}$ was identified below the left main coronary artery (Figure 1). Computed tomography angiography showed that the SVA was $13 \times 12 \times$ $18 \mathrm{~mm}$ with the aortic orifice a few millimeters below the left main coronary artery (Figure 2). The aortic root was $28 \mathrm{~mm}$, sinus Valsalva was $38 \mathrm{~mm}$, sinotubular junction

\footnotetext{
From the Department of Surgery, ${ }^{\mathrm{a}}$ Montreal Heart Institute, Quebec, Canada; University of Montreal, ${ }^{\mathrm{b}}$ Canada; and Department of Cardiothoracic and Vascular Surgery $\mathrm{T}^{\mathrm{c}}$ Aarhus University Hospital, Skejby, Denmark.

Disclosures: Authors have nothing to disclose with regard to commercial support.

Received for publication Dec 30, 2010; revisions received Jan 11, 2011; accepted for publication Jan 24, 2011; available ahead of print March 9, 2011.

Address for reprints: Henrik Jensen, MD, PhD, Department of Surgery, Montreal Heart Institute, 5000, Rue Belanger Montréal, QC H1T 1C8, Canada Qc, Canada (E-mail: hjensen@dadlnet.dk).

J Thorac Cardiovasc Surg 2011;142:219-20

$0022-5223 / \$ 36.00$

Copyright (c) 2011 by The American Association for Thoracic Surgery doi:10.1016/j.jtcvs.2011.01.041
}

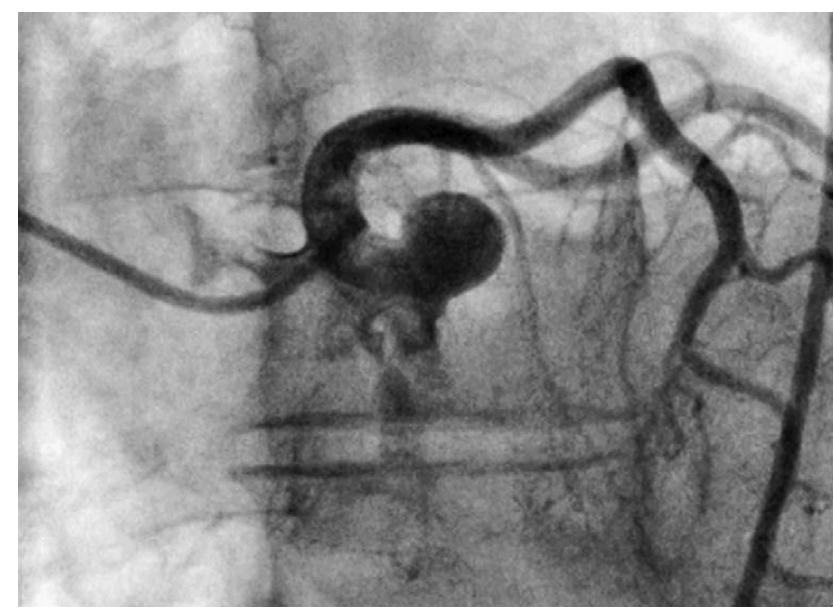

FIGURE 1. Coronary angiogram. A, SVA. B, Left main coronary artery. C, Angiography catheter.

was $31 \mathrm{~mm}$, ascending aorta was $36 \mathrm{~mm}$, aortic arch was $23 \mathrm{~mm}$, and proximal descending aorta was $16 \mathrm{~mm}$ at the point of coarctation patch repair.

\section{CONCLUSIONS}

The diagnosis of SVA in the present case was incidental during coronary angiography. The patient had undergone

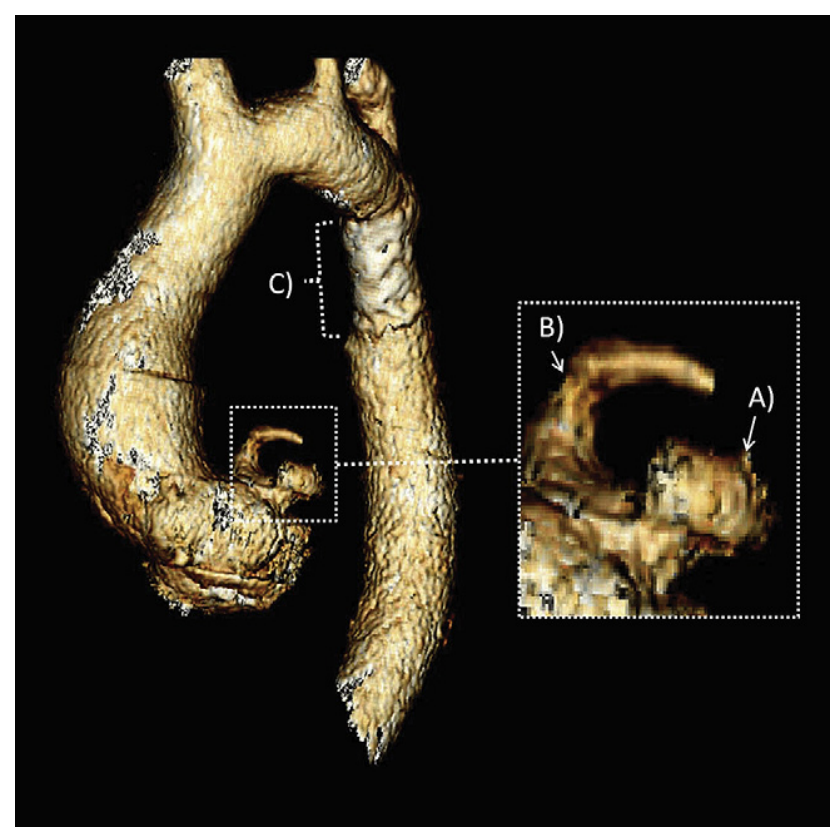

FIGURE 2. Three-dimensional reconstruction of computed tomography angiogram of the thoracic aorta. A, SVA. $B$, Left main coronary artery. $C$, Patch repair of coarctation of the aorta. 
multiple previous examinations in the years before the SVA was diagnosed, including echocardiography, computed tomography angiography, magnetic resonance angiography, and coronary angiography. Perhaps there was a sudden increase in the patient's SVA diameter or, more likely, SVAs are malformations that are easily missed despite careful imaging. A large number of patients may have undiagnosed SVAs.

\section{References}

1. Ott DA. Aneurysm of the sinus of Valsalva. Semin Thorac Cardiovasc Surg Pediatr Card Surg Annu. 2006;165-76.

2. Wang ZJ, Zou CW, Li DC, Li HX, Wang AB, Yuan GD, et al. Surgical repair of sinus of Valsalva aneurysm in Asian patients. Ann Thorac Surg. 2007;84:156-60.

3. Edwards JE, Burchell HB. The pathological anatomy of deficiencies between the aortic root and the heart, including aortic sinus aneurysms. Thorax. 1957;12:125-39.

4. Moustafa S, Mookadam F, Cooper L, Adam G, Zehr K, Stulak J, et al. Sinus of Valsalva aneurysms -47 years of a single center experience and systematic overview of published reports. Am J Cardiol. 2007;99:1159-64. 